\title{
Scc2-mediated loading of cohesin onto chromosomes in G1 yeast cells is insufficient to build cohesion during $\mathrm{S}$ phase
}

\author{
Kim A Nasmyth
}

Department of Biochemistry, Oxford University, South Parks Road, Oxford, OX1 3QU, UK

\section{Summary}

Sister chromatids are held together from their replication until mitosis. Sister chromatid cohesion is mediated by the ring-shaped cohesin complex and it is thought that cohesin holds sister chromatids together by entrapping sister DNAs within the cohesin ring (Haering et al., 2008). However, how this occurs is not well understood. Because cohesin binds to DNA prior to replication it is possible that the replication fork passes through the lumen of the ring thereby placing replicated sisters inside cohesin rings. If this is the case, loading of cohesin in the G1 phase may be sufficient to build cohesion.

We show here that Scc2, a cohesin subunit required for loading cohesin onto chromosomes de novo, is necessary for establishment of cohesion even after Scc2-mediated loading has already taken place during late G1 or early S phase. Our results challenge a previous conclusion based on related experiments whereby Scc2 was found not to be required for cohesion establishment during S phase (Lengronne et al., 2006). 


\section{Introduction}

The notion that sister chromatid cohesion is mediated by co-entrapment of sister chromatin fibres inside individual tripartite cohesin rings (Haering et al., 2008) raises the question of how such structures are generated during $\mathrm{S}$ phase. Are they created de novo following passage of replication forks, or from rings that had previously entrapped unreplicated fibres? If the latter were true, then co-entrapment could in principle arise from passage of replication forks through cohesin rings. This would then explain in simple terms why only sister DNAs are coentrapped. If this is indeed what happens and if as currently believed Scc2 is merely involved in loading cohesin onto chromosomes in the first place, establishment of cohesion during $\mathrm{S}$ phase should take place in the absence of Scc2 function - if cohesin had already loaded onto chromatin.

To test this prediction, we used the temperature sensitive $s c c 2-4$ allele to modulate Scc2 activity as $S$. cerevisiae cells undergo $\mathrm{S}$ phase.

\section{Results}

When cells containing the thermosensitive (ts) scc2-4 (K15021) allele, that are arrested in early G1 using $\alpha$-factor pheromone at the permissive temperature $\left(23^{\circ} \mathrm{C}\right)$ are released into medium lacking the pheromone in the absence of $\mathrm{APC} / \mathrm{C}^{\mathrm{Cdc} 20}$ activity, cells undergo $\mathrm{S}$ phase and subsequently arrest in metaphase with sister chromatids held together by cohesin. Cohesion between sister DNAs was measured by marking the URA3 locus $35 \mathrm{~kb}$ from CEN4 using a tandem array of Tet operators bound by a GFP-tagged Tet repressor. When released at the restrictive temperature $\left(35.5^{\circ} \mathrm{C}\right)$, replication gives rise predominantly to cells with a pair of separated GFP spots, indicating lack of cohesion (Michaelis et al., 1997). In contrast, when released at $23^{\circ} \mathrm{C}$, replication gives rise to cells with a pair of $U R A 3$ loci that are so close together that only a single GFP dot is visible. This confirms that Scc2 is indeed essential for establishing cohesion and that scc2-4 is a bona fide temperature sensitive allele. Importantly, release of wild type $S C C 2$ cells gives rise predominantly to cells with a single GFP dot at both temperatures (results not shown). Due to cleavage of most Scc1 during the preceding anaphase, rather little cohesin is associated with the chromosomes of $\alpha$-factor arrested cells and loading of Scc1 synthesised de novo following release therefore depends on Scc2.

To address whether cohesin loaded at $23^{\circ} \mathrm{C}$ is sufficient to build cohesion at the restrictive temperature $\left(35.5^{\circ} \mathrm{C}\right)$, we released cells from pheromone into medium containing hydroxyurea (HU) at $23^{\circ} \mathrm{C}$, which blocks (or rather greatly delays) DNA replication but nevertheless permits the burst of de novo cohesin loading normally occurring during late G1. After 45 min, cells were transferred to medium lacking $\mathrm{HU}$ at $23^{\circ} \mathrm{C}$ (Fig. 1a), which permitted cells to complete DNA replication (Fig. 1b). Despite loading of cohesin during the $45 \mathrm{~min}$ incubation at $23^{\circ} \mathrm{C}, s c c 2-4$ cells largely failed to establish sister chromatid cohesion when transferred to HU-free medium at restrictive temperature (Fig. 1c). Thus, loading of cohesin in late G1 does not permit cells to generate sister chromatid cohesion during S phase - in the absence of Scc2 activity. It is important to point out that this experiment does not distinguish whether this is due to a requirement of Scc2 during S phase itself or whether Wapl-mediated 
turnover (Chan et al., 2012; Kueng et al., 2006) ensures that Scc2 is continually required to maintain cohesin on chromosomes until the point cells initiate DNA replication.
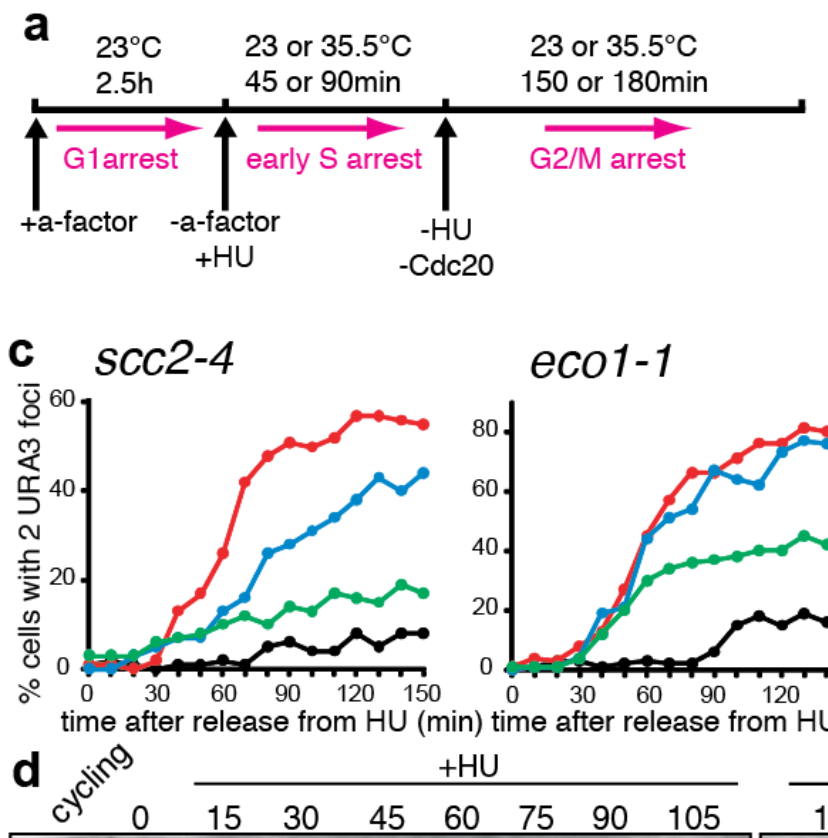

eco1-1
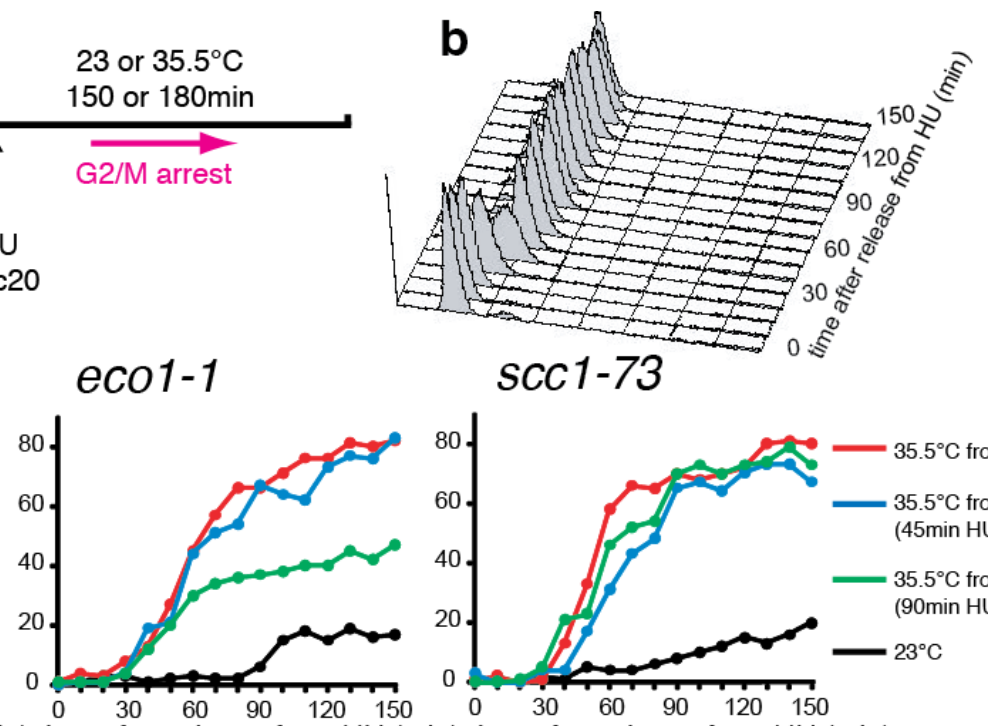

$\operatorname{scc} 1-73$

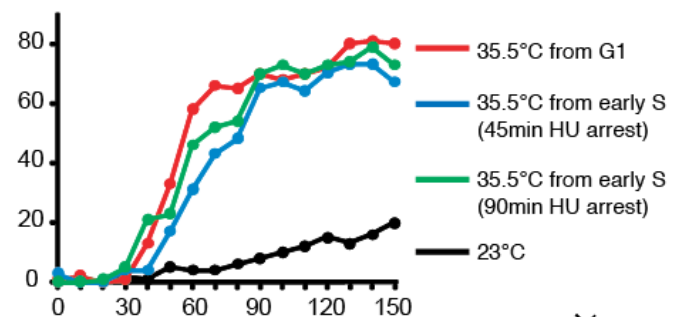

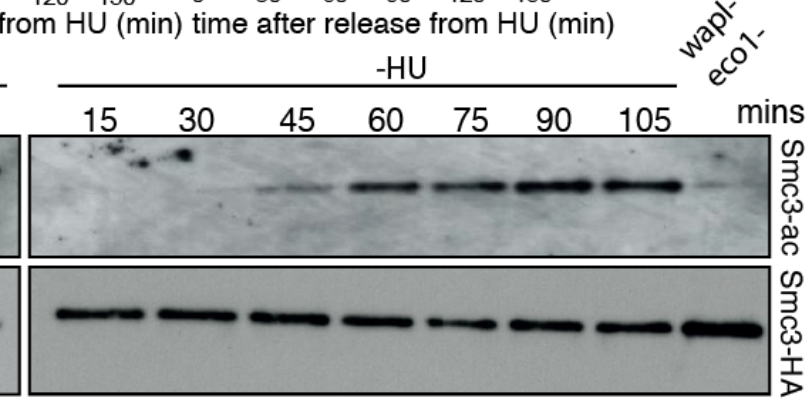

Figure 1: $S$. cerevisiae cells arrested in hydroxyurea (HU) generate sister chromatid cohesion a) Schematic of experimental protocol b) FACS analysis of cells released from HU. c) Percentage of sister chromatid separation measured by counting the fraction of cells with double (split) GFP dots at the URA3 locus in temperature sensitive scc2-4, eco1-1 or scc1-73 mutants. Cells growing at the permissive temperature $\left(23^{\circ} \mathrm{C}\right)$ were first arrested in $\mathrm{G} 1$ by a factor and released at permissive temperature (black), restrictive temperature (red line) or into HU. Cells were held in $\mathrm{HU}$ for 45 (blue) or 90 (green) minutes before being moved to the restrictive temperature $\left(35.5^{\circ} \mathrm{C}\right)$. All cells were then arrested in prometaphase in nocodazole for microscopy. d) Immunoblot of acetylated SMC3-K112/113 of cells arrested for different times in $\mathrm{HU}$

Because a different conclusion concerning Scc2's role during DNA replication has been drawn from similar experiments using a longer incubation period in the presence of $\mathrm{HU}$ (Lengronne et al., 2006), we repeated our experiment, in this case leaving cells in HU for 90 min at $23^{\circ} \mathrm{C}$ before releasing cells into $\mathrm{HU}$-free medium at $35.5^{\circ} \mathrm{C}$. As previously reported and in contrast to the 45 min $\mathrm{HU}$ incubation, this permitted most scc $2-4$ cells to establish cohesion at the restrictive temperature (Fig. 1c). It is known that cells arrested for longer (90 min) periods in HU manage to initiate replication from early origins and build substantial replication forks (Feng et al., 2006). To investigate whether this induces acetylation of Smc3 and thereby an association between cohesin and DNA that is refractory to Wapl, we used Western blotting to measure $\mathrm{Smc} 3$ acetylation following release of cells from pheromone at $23^{\circ} \mathrm{C}$ in the presence or absence of $\mathrm{HU}$. This revealed very little acetylation by $45 \mathrm{~min}$ but substantial acetylation by $90 \mathrm{~min}$ (Fig. 1d), raising the possibility that limited replication accompanied by acetylation of Smc3 by Eco1 and not loading per se is what enables cells to 
build cohesion without further Scc2 activity. To test this, we repeated our temperature shift experiments with ts ecol-1 (K15285) and scc1-73 (K15031) cells (Fig. 1c). SCC1 is required to maintain cohesion as well as to create it. As a consequence, scc1-73 cells failed to establish cohesion either when shifted at $45 \mathrm{~min}$ or at $90 \mathrm{~min}$. In contrast, the behaviour of ecol-1 cells resembled that of $s c c 2-4$ cells, namely about half the cells shifted at 90 min established stable cohesion at $35.5^{\circ} \mathrm{C}$ while few if any did when shifted at $45 \mathrm{~min}$.

Because acetylation accompanies replication, it is difficult to know whether it is replication or acetylation per se that confers cohesion. Crucially, because substantial replication and presumably acetylation of Smc3 occurs in the vicinity of URA3 in cells arrested in HU for 90 min, it is impossible to exclude the possibility that cohesion is in fact fully established on replicated parts of the genome and that this cohesion is either sufficiently close to URA3 to hold sister DNAs together upon release or is capable of translocating into the locus upon release. We suggest that contrary to what has been previously claimed (Lengronne et al., 2006), it is not possible to ascertain from these experiments whether cohesin rings that have loaded onto unreplicated chromatin can create cohesion without further Scc2 activity.

We suggest that future experiments exploring the role of Scc2 during replication would need to address the consequences of inactivating Scc2 as cells enter S phase in cells that had been allowed to load cohesin during late G1. Importantly, such experiments would need to be performed in cells lacking Wapl activity, which would otherwise remove cohesin loaded during G1.

Though our experiments do not permit any definitive conclusion regarding Scc2's role during $\mathrm{S}$ phase, they nevertheless reveal that a previous conclusion to the contrary (Lengronne et al., 2006) must now be regarded as premature.

\section{Experimental Procedures}

The yeast strains used in the split dot assay are derivatives of W303 (K699). The Cells were cultured at $25^{\circ} \mathrm{C}$ in YEP medium with $2 \%$ glucose unless stated otherwise. Hydroxyurea was used at $0.1 \mathrm{M}$. Strains used were as follows:

\begin{tabular}{|l|l|}
\hline Strain ID & Genotype \\
\hline K15021 & MATa \\
& scc2-4 \\
& KanMX::Scc1-PK9 \\
& HIS3::tetR-GFP \\
& URA3::tetOs \\
& TRP1::Met3-Cdc20 \\
\hline K15031 & MATa \\
& scc1-73 \\
& LEU2::tetR-GFP \\
& URA3::tetOs \\
& TRP1::Met3-Cdc20 \\
\hline K15285 & MATa \\
& eco1-1 \\
& LEU2::tetR-GFP \\
& URA3::tetOs \\
& TRP1::Met3-Cdc20 \\
\hline
\end{tabular}




\section{Acknowledgments}

We are grateful to K. Shirahige for supplying anti-acetylated Smc3 antibody. The experiment in Figure 1 a-c was performed by Maria Demidova. The experiment in Figure $1 \mathrm{~d}$ was performed by Frederic Beckouët.

\section{References}

Chan, K.-L., Roig, M.B., Hu, B., Beckouët, F., Metson, J., and Nasmyth, K. (2012). Cohesin's DNA exit gate is distinct from its entrance gate and is regulated by acetylation. Cell 150, 961-974.

Feng, W., Collingwood, D., Boeck, M.E., Fox, L.A., Alvino, G.M., Fangman, W.L., Raghuraman, M.K., and Brewer, B.J. (2006). Genomic mapping of single-stranded DNA in hydroxyurea-challenged yeasts identifies origins of replication. Nat. Cell Biol. 8, 148-155.

Haering, C.H., Farcas, A.-M., Arumugam, P., Metson, J., and Nasmyth, K. (2008). The cohesin ring concatenates sister DNA molecules. Nature 454, 297-301.

Kueng, S., Hegemann, B., Peters, B.H., Lipp, J.J., Schleiffer, A., Mechtler, K., and Peters, J.M. (2006). Wapl controls the dynamic association of cohesin with chromatin. Cell 127, 955967.

Lengronne, A., McIntyre, J., Katou, Y., Kanoh, Y., Hopfner, K.-P., Shirahige, K., and Uhlmann, F. (2006). Establishment of sister chromatid cohesion at the S. cerevisiae replication fork. Mol. Cell 23, 787-799.

Michaelis, C., Ciosk, R., and Nasmyth, K. (1997). Cohesins: chromosomal proteins that prevent premature separation of sister chromatids. Cell 91,35-45. 